\title{
Atypical Cellular Blue Nevus of the Foot: A Case Report
}

\author{
Caroline de Lorenzi $^{a} \quad$ Sandrine Quenan ${ }^{a}$ Yasmine L. Ibrahim ${ }^{b}$ \\ Martin C. Mihm Jr. ${ }^{c} \quad$ Gürkan Kayaa, b \\ a Department of Dermatology, Geneva University Hospitals, Geneva, Switzerland; \\ ${ }^{b}$ Department of Clinical Pathology, Geneva University Hospitals, Geneva, Switzerland; \\ 'Department of Dermatology, Brigham and Women's Hospital, Harvard Medical School, \\ Boston, MA, USA
}

\section{Keywords}

Blue nevus · Atypical nevus

\section{Abstract}

Blue nevus is a congenital and acquired melanocytic proliferation that includes different histological types. The atypical cellular type has been rarely described and it classically has a benign course. However, because of its intermediate features between common blue nevus and malignant blue nevus, long-term clinical follow-up is required. Here we report the case of a 28-year-old woman who presented with an atypical cellular blue nevus on the right foot.

\section{(c) 2019 The Author(s)}

Published by S. Karger AG, Basel

\section{Case Presentation}

We report the case of a 28-year-old woman, with no medical history, who presented with a black skin lesion on the dorsum of the right foot which had appeared in 2009 after an insect bite during her holidays in Brazil. Since then, the lesion had slightly increased in size. Clinical examination revealed a brownish macule with a bluish center that was slightly infiltrated (Fig. 1a). Dermoscopy showed a blue-steel pigmentation in one part and a violaceous color in the other, with hypopigmented areas (Fig. 1b). 

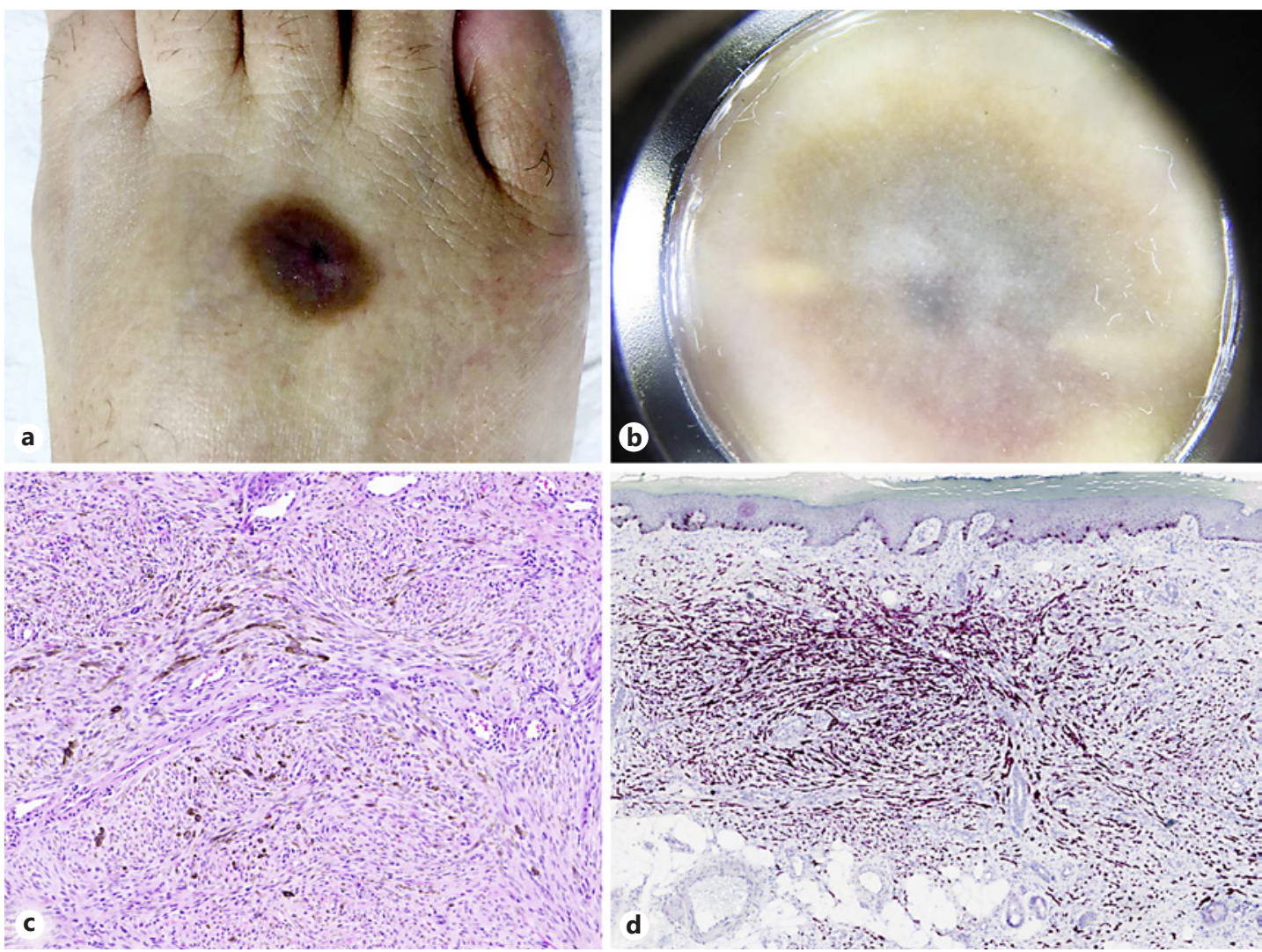

Fig. 1. a Brownish macule with a bluish center on the dorsum of the right foot. b Dermoscopy showing a blue-steel pigmentation in one part and a violaceous color in the other, with hypopigmented areas. c Histology showing dermal proliferation of spindle cells organized in fascicles with a storiform pattern or in nests. H\&E. Original magnification, $\times 10$. $\mathbf{d}$ Melan-A was diffusely positive. Immunohistochemistry. Original magnification, $\times 5$.

A biopsy of the lesion showed dermal proliferation of spindle cells organized in fascicles with a storiform pattern or in nests. Smaller epithelioid cells with nuclei similar to the spindle cells were also present. The lesion infiltrated the subcutaneous fat along with the septa (thickness: $1.9 \mathrm{~mm}$ ). There were no mitoses. S100, SOX10, melan-A, and MITF were diffusely positive. Based on the morphological aspect (Fig. 1a-c) and immunohistochemical profile (Fig. 1d), the diagnosis of atypical blue nevus (BN) with hypercellularity was made. The lesion was surgically removed and exhibited an atypical cellular BN (ACBN).

\section{Discussion and Conclusion}

BN is a congenital and acquired melanocytic proliferation that includes different histological types: common, cellular, atypical cellular, desmoplastic cellular, combined, compound, and malignant [1-3]. First described by Tièche in 1906 [2, 3], this melanocytic lesion usually appears in childhood and rarely before birth [1,3].

Few cases of ACBN have been described [4,5]. The scalp, trunk, buttocks, and extremities are the main localizations reported, and it seems to be more common among women than among men [4]. It is a rare variant of cellular BN, with clinical features resembling classic BN 
and histological features similar to malignant BN [4]. Compared to common BN, ACBN often shows asymmetry on histology, an infiltrating border, and extension into subcutaneous tissue [6]. The lesion exhibits sheet-like growth. However, there is usually a pattern of nesting in the tumoral area that may be highlighted with the use of a reticulin stain. Furthermore, it has a higher proliferative index and higher mitotic rate $[1,6]$. Because of the presence of atypical spindle cells with periadnexal or perineural infiltration and peri- or intratumoral lymphocytic infiltrates, ACBN can be misdiagnosed as malignant melanoma. The absence of a junctional malignant melanocytic component with an intraepidermal pagetoid spread or atypical mitoses helps in diagnosis [4].

A report on 9 cases published by Tran et al. [4] showed that ACBN classically have a benign clinical course, acting as common $\mathrm{BN}$, but because of the intermediate features between common $\mathrm{BN}$ and malignant $\mathrm{BN}$ and their indeterminate nature, complete excision with a 1-cm margin and long-term follow-up are recommended $[1,4]$.

In conclusion, ACBN is a rare lesion that can be difficult to diagnose. Because of its intermediate features, long-term clinical follow-up is required.

\section{Statement of Ethics}

The case report was prepared in compliance with all ethical and confidentiality guidelines and principles.

\section{Disclosure Statement}

The authors declare no conflict of interest.

\section{References}

1 Daltro LR, Yaegashi LB, Freitas RA, Fantini BC, Souza CD. Atypical cellular blue nevus or malignant blue nevus? An Bras Dermatol. 2017 Jan-Feb;92(1):110-2.

2 Muñoz C, Quintero A, Sánchez JL, Ruiz-Santiago H. Persistent blue nevus simulating melanoma. J Am Acad Dermatol. 2004 May;50(5 Suppl):S118-20.

3 Matz H, Orion E, Ruocco V, Wolf R. Clinical simulators of melanoma. Clin Dermatol. 2002 May-Jun;20(3):21221.

4 Tran TA, Carlson JA, Basaca PC, Mihm MC. Cellular blue nevus with atypia (atypical cellular blue nevus): a clinicopathologic study of nine cases. J Cutan Pathol. 1998 May;25(5):252-8.

5 Özdemir ED, Yalçınkaya C, Çoban G, Canpolat T, Okçu Heper A, Çelik H. A rare lesion of the clitoris: atypical cellular blue naevus: case report. J Obstet Gynaecol. 2017 Jan;37(1):121-2.

6 Shumway BS, Rawal YB, Allen CM, Kalmar JR, Magro CM. Oral atypical cellular blue nevus: an infiltrative melanocytic proliferation. Head Neck Pathol. 2013 Jun;7(2):171-7. 